\title{
COMPREENDENDO OS SIGNIFICADOS DE SE CONVIVER COM FERIDA CRÔNICA
}

\section{UNDERSTANDING THE MEANINGS OF LIVING WITH CHRONIC WOUND ENTENDIENDO LOS SIGNIFICADOS DE SI CONVIVIR LA HERIDA CRÓNICA}

\author{
Efigênia Gomes ${ }^{1}$, Miguir Terezinha Vieccelli Donoso ${ }^{2}$, Andreza Werli-Alvarenga ${ }^{3}$, Vânia Regina Goveia ${ }^{4}$
}

\begin{abstract}
RESUMO
Objetivo: Identificar significados de se ter uma lesão crônica, numa perspectiva compreensiva. Método: Utilizou-se a metassíntese. Foram buscados estudos que atendessem aos seguintes critérios: artigos primários; qualitativos; nos idiomas português, inglês ou espanhol; publicados no período de 2006 a 2016 e que abordassem o tema lesões crônicas. Resultados: A ocorrência de lesão crônica afeta aspectos que vão além do biológico, influenciando nas relações sociais, familiares, na autoestima, sexualidade e na percepção da pessoa sobre si mesma. As categorias emergentes foram recorrentes em mais de um artigo, o que sugere cenários semelhantes para diversas pessoas com lesão crônica. As limitações, o sofrimento no cotidiano e as relações sociais foram questões encontradas nas várias categorias emergentes. Conclusão: O universo da pessoa com lesão crônica apresenta-se marcado por questões que extrapolam a dor e as características da lesão. O enfermeiro deve abordar essas pessoas em uma perspectiva integral e holística.
\end{abstract}

Descritores: Ferimentos e Lesões; Emoções; Enfermagem.

\begin{abstract}
Objective: To identify meanings of having a chronic lesion through an understandable perspective. Method: The metassynthesis was used. We sought studies that met the following criteria: primary articles; quality; in Portuguese, English or Spanish; published in the period from 2006 to 2016 and that address the theme chronic injuries. Results: The incidence of chronic lesion affects aspects which go beyond the biological, influencing the social relations, family, in self-esteem, sexuality and the perception of the person about himself. The emerging categories were applicants in more than one article, what suggests similar scenarios for various people with chronic lesion. The limitations, suffering in everyday life and social
\end{abstract}

\footnotetext{
${ }^{1}$ Enfermeira estomaterapeuta pela Escola de Enfermagem da UFMG.

${ }^{2}$ Doutora em Ciências da Saúde pela Faculdade de Medicina da UFMG. Professora associada do Departamento de Enfermagem Básica da Escola de Enfermagem da UFMG (autor correspondente). Fone (31) 34099177. E.mail: miguir@enf.ufmg.br

${ }^{3}$ Doutora em Enfermagem pela Escola de Enfermagem da UFMG. Professora adjunta do Departamento de Enfermagem Básica da Escola de Enfermagem da UFMG.

${ }^{4}$ Doutora em Enfermagem pela Escola de Enfermagem da USP. Professora adjunta do Departamento de Enfermagem Básica da Escola de Enfermagem da UFMG.
} 
relations were frequently found in several emerging categories. Conclusion: The universe of the person with chronic lesion is marked by issues that go beyond pain and the characteristics of the lesion. The nurse must address these people in a comprehensive and holistic perspective.

Descriptors: Wounds and Injuries; Emotions; Nursing.

\section{RESUMEN}

Objetivo: Identificar significados de tener una lesión crónica, en una perspectiva comprensiva. Método: Se utilizó la metassíntesis. Se buscó estudios que cumplan los siguientes criterios: artículos primarios; de calidad; en los idiomas portugués, inglés o español; publicados en el período de 2006 a 2016 y que abordaran el tema lesiones crónicas. Resultados: La ocurrencia de lesión crónica afecta aspectos que van más allá de lo biológico, influenciando en las relaciones sociales, familiares, en la autoestima, sexualidad y en la percepción de la persona sobre sí misma. Las categorías emergentes fueron recurrentes en más de un artículo, lo que sugiere escenarios similares para diversas personas con lesión crónica. Las limitaciones, el sufrimiento en el cotidiano y las relaciones sociales fueron cuestiones encontradas en las diversas categorías emergentes. Conclusión: El universo de la persona con lesión crónica se presenta marcado por cuestiones que extrapolan el dolor y las características de la lesión. El enfermero debe abordar a estas personas por medio de una perspectiva integral y holística.

Descriptores: Heridas y lesiones; Emociones; Enfermería.

\section{INTRODUÇÃO}

Feridas de ocorrências crônicas são capazes de gerar impactos emocionais, físicos, sociais e econômicos, gerando uma série de mudanças na vida da pessoa, tais como o isolamento social, sessões diárias de trocas de curativos, alterações na deambulação e atividades físicas, especialmente os distúrbios da autoimagem, provocando a desmotivação e incapacitando o convívio social. ${ }^{1}$

Algumas vezes, a presença de feridas crônicas resulta em mudanças na aparência física, provocando diferentes reações em pacientes, amigos e familiares. Cada indivíduo enxerga seu próprio corpo de maneira única, sendo que a imagem corporal pode ser entendida como a figuração do corpo do indivíduo formada na sua mente, ou seja, como o corpo se apresenta para o sujeito. ${ }^{2}$ A imagem corporal tem relação com a auto aceitação.

Ao apresentar uma ferida crônica, a pessoa pode desenvolver sentimentos negativos como tristeza, insatisfação, frustração, ansiedade, raiva, depressão, constrangimento, isolamento, sensação de incapacidade, dificuldade de relacionamento interpessoal, prejuízo na imagem corporal e na atividade sexual. ${ }^{3}$ Possuir uma ferida crônica traz uma série de mudanças na vida do indivíduo, como isolamento social, necessidade de adaptação às sessões diárias de curativos, 
alterações na atividade física e deambulação, abstenções alimentares, uso de medicamentos contínuos e, especialmente, distúrbios de autoimagem. ${ }^{4}$

Dessa forma, o problema de pesquisa aqui estabelecido foi: a atenção da pessoa com ferida crônica vai além das intervenções voltadas para as lesões teciduais, exigindo que o enfermeiro atue na identificação de estratégias para o enfrentamento deste agravo. Para tal, fazse necessário identificar os significados de ser um sujeito com lesões crônicas. Assim, este trabalho teve como objetivo compreender os significados de se conviver com ferida crônica.

Compreendendo estes significados, o enfermeiro e os demais membros da equipe de saúde poderão atuar de forma holística junto ao sujeito com este agravo.

\section{MÉTODO}

O referencial metodológico utilizado foi a metassíntese. Este referencial permite integrar artigos qualitativos, ou seja, que vão além da soma das partes, uma vez que oferecem nova interpretação, que não pode ser encontrada em nenhum relatório primário, pois todos os artigos tornaram-se uma única amostra. ${ }^{5}$

Neste estudo, o problema de pesquisa gerou a seguinte questão norteadora: quais os significados para o sujeito de se conviver com ferida crônica?

Para compor a amostra realizou-se pesquisa avançada na Biblioteca Virtual em Saúde (BVS), onde se cruzaram os descritores: Pesquisa qualitativa; Enfermagem; Feridas; Curativos; Doenças crônicas; Sentimentos. Buscaram-se os descritores nos bancos de dados Medical Literature Analysis and Retrieval System Online (MEDLINE), Literatura LatinoAmericana e do Caribe em Ciências da Saúde (LILACS), Base de Dados de Enfermagem (BDENF), Indice Bibliográfico Español de Ciencias de la Salud (IBECS) e Secretaria Estadual de Saúde de São Paulo. Foram buscados estudos que atendessem aos seguintes critérios: artigos primários; na linha qualitativa; nos idiomas português, inglês ou espanhol; publicados no período de 2006 a 2016 em periódicos científicos e que abordassem o tema lesões crônicas.

A seguir, apresenta-se diagrama contendo a estratégia de busca: 
Figura 1 - Diagrama da seleção de artigos para revisão integrativa. Belo Horizonte, 2017

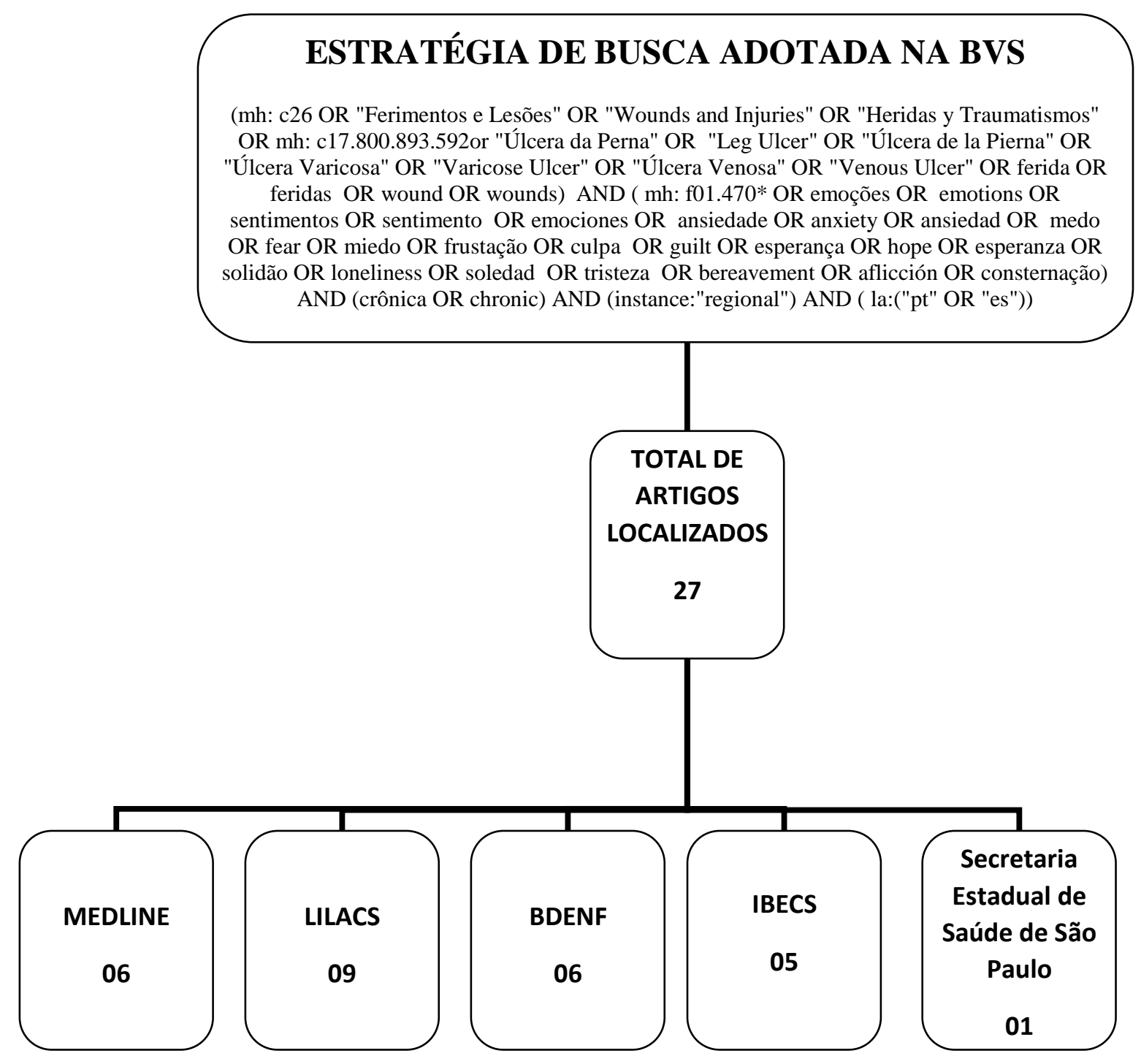

Fonte: Autoras.

\section{RESULTADOS}

Dos 27 artigos encontrados, 19 foram excluídos pelos seguintes motivos: três artigos eram artigos de revisão, 15 eram pesquisas quantitativas e um artigo tratava das percepções dos profissionais e não dos sujeitos com lesões crônicas. Dessa forma, nove artigos compuseram esta revisão integrativa.

Um artigo usou como referencial metodológico a fenomenologia, um utilizou a teoria das representações sociais 
e sete artigos utilizaram a análise de conteúdo na sua modalidade temática.

Quanto à origem, um era cubano e oito eram brasileiros. Um dos periódicos (Journal of Research Fundamental Care Online), apesar de utilizar o idioma inglês, trata-se de periódico brasileiro.

A maioria dos artigos foi escrita por enfermeiros, cuja titulação variou de graduado a doutor. Os anos de publicação, em ordem cronológica foram de 2011 a 2016.

Por questões didáticas, estes artigos foram codificados como Artigo 1, Artigo 2, Artigo 3, Artigo 4, Artigo 5, Artigo 6, Artigo 7, Artigo 8 e Artigo 9.

Os artigos encontram-se apresentados a seguir, na forma de quadro sinóptico, ressaltando-se que este quadro apresenta os títulos dos artigos e suas respectivas categorias temáticas, geradas pelas falas dos depoentes. 
Quadro 1 - Quadro sinóptico dos artigos científicos incluídos na amostra. Belo Horizonte, 2017.

\begin{tabular}{|c|c|}
\hline Artigo & Categorias temáticas originadas em cada artigo \\
\hline $\begin{array}{l}\text { Artigo 1: Repercussões sociais pela } \\
\text { pessoa idosa com úlcera venosa }{ }^{6} \text {. }\end{array}$ & $\begin{array}{l}\text { 1) Enfrentando preconceitos; } \\
\text { 2) Vivenciando constrangimentos e vergonha social. }\end{array}$ \\
\hline $\begin{array}{l}\text { Artigo 2: Sentimentos de inclusão social } \\
\text { de pessoas com úlcera venosa }{ }^{7} \text {. }\end{array}$ & $\begin{array}{l}\text { 1) Sofrimento; } \\
\text { 2) Lazer é assistir televisão; } \\
\text { 3) A úlcera não exclui a pessoa da sociedade; } \\
\text { 4) A úlcera gera isolamento social. }\end{array}$ \\
\hline $\begin{array}{l}\text { Artigo 3: Alterações ocorridas no } \\
\text { cotidiano de pessoas acometidas pela } \\
\text { úlcera venosa: contribuições à } \\
\text { enfermagem }\end{array}$ & $\begin{array}{l}\text { 1) O impacto das frequentes recidivas da úlcera venosa; } \\
\text { 2) Tendência ao isolamento social; } \\
\text { 3) A repercussão das limitações no cotidiano. }\end{array}$ \\
\hline $\begin{array}{l}\text { Artigo 4: Ser mulher e ter o corpo ferido: } \\
\text { um estudo de representações sociais }{ }^{9} \text {. }\end{array}$ & $\begin{array}{l}\text { 1) Ter o corpo marcado e estigmatizado; } \\
\text { 2) Viver com dor; } \\
\text { 3) Ser triste e sozinho; } \\
\text { 4) Viver irritada com tudo e com todos; } \\
\text { 5) Ser dependente dos outros. }\end{array}$ \\
\hline $\begin{array}{l}\text { Artigo 5: Experiências construídas no } \\
\text { processo de viver com a úlcera venosa }{ }^{10} \text {. }\end{array}$ & $\begin{array}{l}\text { 1) Úlcera venosa e a sua repercussão no trabalho; } \\
\text { 2) Mudanças na rotina e limitaçôes no viver com a úlcera venosa; } \\
\text { 3) Conviver com a úlcera venosa e a necessidade de cuidado } \\
\text { profissional e familiar. }\end{array}$ \\
\hline $\begin{array}{l}\text { Artigo 6: Trajetórias afetivo-sexuais de } \\
\text { pessoas com feridas crônicas nos } \\
\text { membros inferiores: aspectos na escuta } \\
\text { terapêutica }{ }^{11} \text {. }\end{array}$ & $\begin{array}{l}\text { 1) Trajetórias afetos-sexuais solitárias; } \\
\text { 2) Trajetórias afeto-sexuais fragmentadas; } \\
\text { 3) Trajetórias afeto-sexuais lineares ou contínuas. }\end{array}$ \\
\hline $\begin{array}{l}\text { Artigo 7: O cotidiano do homem que } \\
\text { convive com a úlcera venosa crônica: } \\
\text { estudo fenomenológico }{ }^{12} \text {. }\end{array}$ & $\begin{array}{l}\text { 1) Restrições na vida social; } \\
\text { 2) Recuperar a integridade da pele e retomar as atividades. }\end{array}$ \\
\hline $\begin{array}{l}\text { Artigo 8: O cotidiano do indivíduo com } \\
\text { ferida crônica e sua saúde mental }{ }^{13} \text {. }\end{array}$ & $\begin{array}{l}\text { 1) Viver com a dor: uma experiência para além do visível; } \\
\text { 2) Convivendo com a ferida: uma rotina de expectativas; } \\
\text { 3) Religiosidade como forma de enfrentamento da realidade; } \\
\text { 4) A ferida crônica e sua repercussão no relacionamento familiar; } \\
\text { 5) Mudanças de hábitos interferindo na saúde mental. }\end{array}$ \\
\hline $\begin{array}{l}\text { Artigo 9: Significado da ferida para } \\
\text { portadores de úlceras crônicas }{ }^{14} \text {. }\end{array}$ & $\begin{array}{l}\text { 1) Sensações marcantes; } \\
\text { 2) O cotidiano e a ferida crônica; } \\
\text { 3) O impacto emocional. }\end{array}$ \\
\hline
\end{tabular}

Fonte: autoras.

dentre outras. O cuidado com pessoas que apresentam feridas crônicas é uma atividade do cotidiano do enfermeiro e ao

\section{DISCUSSÃO}

As categorias que emergiram abordaram diversos aspectos, tais como relacionamentos interpessoais, vida social, sexualidade e dependência de cuidadores, mesmo tempo um desafio: requer conhecimento específico, habilidade e abordagem holística. ${ }^{15} \mathrm{O}$ preconceito e o estigma foram abordados pelos Artigos $1 \mathrm{e}$ 4. O Artigo 1 refere-se à ferida como algo 
contagioso, o que pode gerar rejeição. $\mathrm{O}$ Artigo 4 discorre sobre o corpo marcado e estigmatizado, também relacionado à rejeição, ou seja, o preconceito decorrente da aparência e do odor da ferida. À reflexão sobre pessoas com lesões crônicas e seu cotidiano, é notório o uso de estigmas e atitudes preconceituosas perante as mesmas. No entanto, faz-se necessário promover a inclusão social. O contato com as diferenças significativas propiciado pela inclusão, desde que criado um ambiente inclusivo, pode minimizar o preconceito e colaborar na criação de uma sociedade melhor. ${ }^{16}$

A questão da vergonha emergiu no Artigo 1. A vergonha é abordada em trabalho qualitativo ${ }^{17}$ sob a perspectiva do embaraço e da humilhação, sentimentos que podem ser atribuídos ao sujeito que se sente diferente. As probabilidades das pessoas se sentirem incômodas em seus próprios corpos podem manifestar-se como mal estar, timidez ou vergonha. Lembra-se que a lesão crônica envolve odor fétido, mobilidade reduzida, aparência física modificada, ou seja, condições que predispõem ao sentimento de vergonha.

$\mathrm{O}$ isolamento e as restrições na vida social foram recorrentes, pois emergiram nos Artigos 2, 3, 4 e 7. O Artigo 2 aborda a geração de isolamento social pela presença de ferida crônica. No entanto, também no Artigo 2 emerge a categoria "A úlcera não exclui a pessoa da sociedade". Na pesquisa qualitativa, há possibilidades de emersão de várias opiniões, que podem se contrapor entre si. $\mathrm{O}$ isolamento social também é abordado na literatura $^{18}$ como sendo comum às pessoas nessas condições. Frequentemente, o distanciamento entre os indivíduos é intensificado pela visão estigmatizadora que a sociedade tem da pessoa com lesão, podendo ter repercussões no seu cotidiano. ${ }^{19}$ Ainda o Artigo 2 se refere ao isolamento social como referente ao convívio familiar, social e até mesmo intrínseco ao próprio ser.

A dor emergiu nos Artigos 4 e 8. A dor pode ser definida como uma experiência subjetiva associada à lesão real ou potencial nos tecidos, podendo ser descrita tanto em termos destas lesões quanto por ambas as características. ${ }^{20} \mathrm{O}$ Artigo 4 se refere à dor na perspectiva do sofrimento, seja ele físico ou não. Segundo seus autores, a dor está presente em diferentes situações cotidianas, tais como mal estar geral, lembrança desagradável, angústia e sofrimento. A dor não abrange apenas a dimensão física, mas tem também dimensões emocionais. Lembra-se que quem sofre com a dor tem alterações biológicas, psicossociais e 
psicossomáticas. ${ }^{21}$ No Artigo 8, os autores discorrem sobre a dor como algo referente ao momento que conduz à pessoa a lembrança de um martírio, algo que trás significado negativo, mal estar, angústia, ou seja, um marcador que evidencia esgotamento de sua capacidade enquanto se humano. A questão da dor é abrangente e merece maiores estudos em função de sua subjetividade e amplitude. Nas relações pessoais, existem variadas formas de compartilhar a dor: atividades motoras, expressões faciais, alterações posturais, respostas autonômicas e expressões paralinguísticas (como gemer, suspirar). Este conjunto representa a linguagem da dor. $^{22}$

A dependência de outras pessoas, sejam familiares ou profissionais cuidadores emergiu nos Artigos 4 e 5. A dependência deve ser avaliada e ressignificada em ambos as direções: sujeito cuidado e sujeito cuidador. Ressalta-se que há pessoas que necessitaram reestruturar toda uma forma de vida para prestar o cuidado, privando-se de tempo de lazer, de exercer uma atividade laboral, sacrificando sua rotina pessoal e, muitas vezes, sua saúde física, emocional e social. $^{23}$

O Artigo 4 enfatiza as limitações físicas, acarretando dependência inclusive para vestir-se, em alguns casos, gerando sentimentos de incapacidade, inutilidade e a perda da liberdade. No Artigo 5, alguns entrevistados destacam a necessidade de determinados cuidados, sejam provenientes de profissional ou de familiar, imbuída na condição de se ter um agravo crônico. O enfrentamento dos problemas decorrentes de doenças incapacitantes pode ocasionar uma desorganização no funcionamento familiar, interferindo na dinâmica da família. $^{23}$

As três categorias emergentes no Artigo 6 são referentes à sexualidade. Segundo as autoras, a análise permitiu apreender: trajetórias afetivo-sexuais solitárias, trajetórias fragmentadas e trajetórias lineares ou contínuas. O sexo foi referido como uma prática solitária para aqueles cujas feridas se iniciaram na infância ou adolescência, sendo que a experiência sexual a dois mostrou-se inexistente. As trajetórias afetivo-sexuais fragmentadas foram apreendidas nas narrativas dos participantes que desenvolveram a ferida na fase adulta. Já nas trajetórias afetivo-sexuais lineares ou contínuas, as pessoas que ingressaram em experiências sexuais antes de desenvolver a ferida mostraram-se com maior potencial de esperança. Desta forma, infere-se que o momento de vida em que a ferida apareceu 
interfere diretamente na questão da sexualidade. Porém, há um aspecto a ser considerado: a sexualidade não se refere unicamente ao ato sexual. Em pesquisa sobre sexualidade de pessoas com ferida crônica ${ }^{3}$ emergiu uma categoria referente ao entendimento sobre sexualidade. Os participantes significaram o termo sexualidade como sinônimo de sexo/ato sexual em si. Entretanto, quando se fala sobre sexo e sexualidade, é preciso compreender que a sexualidade é parte integrante e indissociável da pessoa, não implicando necessariamente em seu aspecto reprodutivo, focado no ato sexual. ${ }^{24} \mathrm{~A}$ sexualidade vai muito além do ato sexual.

As limitações no cotidiano emergiram no Artigo 3, Artigo 5 e, subjetivamente no Artigo 2, que se refere a ver televisão como única opção de lazer, configurando a limitação deste. Possuir uma ferida crônica traz uma série de mudanças na vida do indivíduo, tais como o isolamento social, as alterações na atividade física e deambulação, as abstenções alimentares, o uso de medicamentos contínuos e, especialmente, os distúrbios de autoimagem. Tais alterações provocam a desmotivação e a incapacidade para o autocuidado, e para as atividades de vida e de convívio social. ${ }^{1}$
O Artigo 8 trouxe a categoria "Relacionamento familiar". Os autores observaram que a ferida pode interferir nas relações dentro da própria família, sendo que esse achado é corroborado em pesquisa quantitativa ${ }^{25}$, que se refere ao impacto social da ferida crônica, mostrando que os pacientes se sentem discriminados inclusive pela família. Entretanto, o Artigo 2 apresentou a categoria "A úlcera não exclui a pessoa da sociedade", em uma perspectiva positiva. Existem várias formas da pessoa com lesão crônica conviver em sociedade, desenvolvendo o autocuidado e favorecendo o convívio familiar. ${ }^{26}$

As repercussões nas atividades de trabalho emergiram no Artigo 5 e no Artigo 7. As restrições nas atividades de vida diária, em especial no trabalho foram discutidas em revisão integrativa sobre qualidade de vida de pacientes com úlcera venosa. $^{27}$ Para os autores, é possível melhorar a qualidade de vida e a reinserção dessas pessoas nos seus meios sociais e no trabalho. Assim, os profissionais da saúde podem atuar de várias formas, favorecendo o processo de inclusão e reinserção social dessas pessoas.

A questão do impacto foi recorrente, emergindo nos Artigos 9 e 3. De acordo com o Artigo 9, o impacto emocional 
causado pela ferida também não cicatriza. É crônico. A ferida crônica causa ao portador sensação de desânimo, perda, cansaço e até depressão. Em estudo sobre impacto das pessoas frente ao diagnóstico de hanseníase ${ }^{28}$, há referência do impacto deste diagnóstico, referindo-se às fragilidades destas pessoas no referido momento. Entende-se como impacto algo que produza um efeito forte, marcante. $\mathrm{O}$ Artigo 3 se refere aos impactos frente às recidivas da lesão, sugerindo que, a cada nova recidiva, o impacto "reacontece". Isto deve ser considerado na visão sobre a pessoa na prática do cuidado. Lembra-se que o cuidado, enquanto essência da integralidade do ser, deve contemplar a pessoa humana nos aspectos biopsicológico, emocional, social, cultural e espiritual. $^{29}$

A religiosidade não foi recorrente, tendo emergido apenas no Artigo 8. No entanto, faz-se necessário discutir a questão da religiosidade, que pode ou não interferir na vida das pessoas com lesão crônica. O enfermeiro, durante o atendimento, deve indagar sobre a religiosidade da pessoa com lesão ou com quaisquer agravos, uma vez que no universo do paciente, esta pode ser um suporte emocional e espiritual. A religiosidade é reconhecida como sustento e conforto para o paciente e seus familiares enfrentarem a situação de adoecimento. ${ }^{30}$

\section{CONSIDERAÇÕES FINAIS}

Ao final deste trabalho, pode-se concluir que a pessoa com lesão crônica não apresenta apenas uma lesão de caráter histológico e patológico. Ter lesão crônica envolve déficit de autoestima, inaptidão para o trabalho, relacionamentos sociais, relacionamento com os familiares, questões relacionadas à sexualidade e às emoções. O sentimento de impotência faz com que os pacientes desenvolvam sofrimentos psíquicos, interferindo em sua forma de se relacionar com outras pessoas.

Há que se ressaltar que estes pacientes devem ser incluídos em grupos de apoio e rede especializada mais acessível, conferindo-lhes suporte assistencial que lhes garanta atividades e desenvolvimento de vida produtiva e adequada às suas limitações.

O universo da pessoa com lesão crônica apresenta-se marcado por questões que extrapolam a dor e as características da lesão. O enfermeiro deve abordar essas pessoas em uma perspectiva integral e holística, de forma a prestar um atendimento diferenciado, interdisciplinar e capaz de auxiliá-las no enfrentamento das adversidades da convivência com lesão 
crônica, planejando e humanizando a assistência, repercutindo na qualidade de vida.

\section{REFERÊNCIAS}

1. Albuquerque ER, Alves EF. Análise da produção bibliográfica sobre qualidade de vida de portadores de feridas crônicas. Saúde e Pesqui. [Internet]. maio/jun 2011 [citado em 01 abr 2017]; 4(2):147-52. Disponível em: http://recil.grupolusofona.pt/jspui/handle/1 0437/2973

2. Silva CJA, Freire MWS, Simpson CA, Silva FS, Ferraz JB. Sentimentos vivenciados por mulheres vítimas de queimaduras: revisão integrativa. Rev Pesqui Cuid Fundam. [Internet]. 2015 dez [citado em 01 set 2017]; 7(supl):56-64. Disponível em:

http://www.seer.unirio.br/index.php/cuidad ofundamental/article/view/5885/pdf_1 Souza MKB, Matos IAT. Percepção do portador de ferida crônica sobre a sua sexualidade. Rev Enferm UERJ. [Internet]. jan/mar 2010 [citado em 01 set 2017]; 18(1):19-24. Disponível em: http://www.facenf.uerj.br/v18n1/v18n1a04 .pdf

4. Bedin LF, Busanello J, Sehnem GD, Silva FM, Poll MA. Estratégias de promoção da autoestima, autonomia e autocuidado das pessoas com feridas crônicas. Rev Gaúch Enferm. [Internet]. set 2014 [citado em 26 jun 2017]; 35(3):61-7. Disponível em: http://www.scielo.br/pdf/rgenf/v35n3/pt_1 983-1447-rgenf-35-03-00061.pdf

5. Matheus MCC. Metassíntese qualitativa: desenvolvimento e contribuições para a prática baseada em evidências. Acta Paul Enferm. [Internet]. 2009 [citado em 01 set 2017]; 22(n esp1):543-5. Disponível em: http://www.scielo.br/pdf/ape/v22nspe1/19. pdf
6. Aguiar ACS, Sadigursky D, Martins LA, Menezes TMO, Santos ALS, Reis LA. Repercussões sociais vivenciadas pela pessoa idosa com úlcera venosa. Rev Gaúch Enferm. [Internet]. set 2016 [citado em 01 set 2017]; 37(3):e55302. Disponível em:

http://www.scielo.br/pdf/rgenf/v37n3/0102 -6933-rgenf-1983-144720160355302.pdf

7. Alves JFA, Sousa ATO, Soares MJGO.

Sentimentos de inclusão social de pessoas com úlcera venosa. Rev Enferm UFSM. [Internet]. abr/jun 2015 [citado em 07 set 2017]; 5(2):192-203. Disponível em: https://periodicos.ufsm.br/reufsm/article/vi ew/15425/pdf

8. Aguiar ACSA, Amaral L, Reis LA, Barbosa TSM, Camargo CL, Alves MR, et al. Alterações ocorridas no cotidiano de pessoas acometidas pela úlcera venosa: contribuições à enfermagem. Rev Cuba Enferm. [Internet]. jul/set 2014 [citado em 05 jun 2017]; 30(3):213-21. Disponível em:

http://www.revenfermeria.sld.cu/index.php /enf/article/view/510/98

9. Alves RM, Carvalho ESS, Santos LM, Araújo EM. Ser mulher e ter o corpo ferido: um estudo de representações sociais. Rev Pesqui Cuid Fundam. [Internet]. out/nov 2014 [citado em 18 jul 2017]; 6(4):1513-24. Disponível em: http://www.redalyc.org/pdf/5057/5057507 70017.pdf

10. Silva DC, Budó MLD, Schmith MD, Ecco L, Costa UKF, Torres GV. . Experiências construídas no processo de viver com a úlcera venosa. Cogitare Enferm. [Internet]. jan/mar 2015 [citado em 11 ago 2017]; 20(1):13-19. Disponível em:

http://revistas.ufpr.br/cogitare/article/view/ 37784/24829

11. Carvalho ES, Paiva MS, Aparício EC, Rodrigues GRS. Trajetórias afetivosexuais de pessoas com feridas crônicas nos membros inferiores: aspectos na escuta 
terapêutica. Rev Gaúch Enferm. [Internet]. set 2013 [citado em 18 ago 2017];

34(3):163-70. Disponível em:

http://www.scielo.br/pdf/rgenf/v34n3/a21v 34n3.pdf

12. Silva MH, Jesus MCP, Merighi MAB, Oliveira DM, Biscotto PR, Silva GPS. O cotidiano do homem que convive com a úlcera venosa crônica: estudo fenomenológico. Rev Gaúch Enferm. [Internet]. set 2013 [citado em 30 mar 2017]; 34(3):95-101. Disponível em: http://www.scielo.br/pdf/rgenf/v34n3/a12v 34n3.pdf

13. Waidman MAP, Rocha SC, Correa JL, Brischiliari A, Marcon SS. O cotidiano do indivíduo com ferida crônica e sua saúde mental. Texto \& Contexto Enferm. [Internet]. 2011 [citado em 15 set 2017]; 20(4):691-9. Disponível:

http://www.scielo.br/pdf/tce/v20n4/07.pdf 14. Lara MO, Pereira Junior AC, Pinto JSF, Vieira NF, Wichr P. Significado da ferida para portadores de úlcera crônica. Cogitare Enferm. [Internet]. jul/set 2011 [citado em 15 set 2017]; 16(3):471-7. Disponível em:

http://revistas.ufpr.br/cogitare/article/view/ 20178/16232

15. Brito KKG, Sousa MJ, Sousa ATO, Meneses LBA, Oliveira SHS, Soares MJGO. Feridas crônicas: abordagem da enfermagem na produção científica da pós graduação. Rev Enferm UFPE. [Internet]. fev 2013 [citado em 07 set 2017]; 7(2):414-21. Disponível em: https://periodicos.ufpe.br/revistas/revistaen fermagem/article/view/10250/10863 16. Oliva DV. Raízes sociais e psicodinâmicas do preconceito e suas implicações na educação inclusive. Psicol Esc Educ. [Internet]. maio/ago 2016 [citado em 03 set 2017]; 20(2):349-56. Disponível em: http://www.scielo.br/pdf/pee/v20n2/21753539-pee-20-02-00349.pdf
17. Verztman J. Embaraço, humilhação e transparência psíquica: o tímido e sua dependência do olhar. Ágora [Internet]. jan/ago 2014 [citado em 03 set 2017]; 17(n esp); 127-40. Disponível em: http://www.scielo.br/pdf/agora/v17nspe/11 .pdf

18. Figueiredo ML, Zuffi FB. Cuidados aos portadores de úlcera venosa: percepção dos enfermeiros da Estratégia de Saúde da Família. Enferm Glob. [Internet]. out 2012 [citado em 07 set 2017]; (28):147-58.

Disponível em:

http://scielo.isciii.es/pdf/eg/v11n28/pt_doc encia4.pdf

19. Salomé GM. Processo de viver do portador com ferida crônica: atividades recreativas, sexuais, vida social e familiar. Saúde Colet. [Internet]. 2010 [citado em 15 set 2017]; 7(46):300-4. Disponível em: http://www.redalyc.org/articulo.oa? $\mathrm{id}=842$ 15678004

20. Silva JA, Ribeiro Filho NP. A dor como um problema psicofísico. Rev Dor [Internet]. abr/jun 2011 [citado em 11 ago 2017]; 12(2):138-151. Disponível em: http://www.scielo.br/pdf/rdor/v12n2/v12n2 a11

21. Araújo LC, Romero B. Dor: avaliação do $5^{\circ}$ sinal vital. Uma reflexão teórica. Rev Dor [Internet]. out/dez 2015 [citado em 30 mar 2017]; 16(4):291-6. Disponível em: http://www.scielo.br/pdf/rdor/v16n4/pt_18 06-0013-rdor-16-04-0291.pdf

22. Márquez JO. A dor e os seus aspectos multidimensionais. Ciênc Cult. [Internet]. abr 2011 [citado em 30 ago 2017]; 63(2):28-32. Disponível em: http://cienciaecultura.bvs.br/pdf/cic/v63n2/ a10v63n2.pdf

23. Souza LR, Hanus JS, Dela Libera LB, Silva VM, Mangilli EM, Simões PW, Ceretta LB, Tuon L. Sobrecarga no cuidado, estresse e impacto na qualidade de vida de cuidadores domiciliares assistidos na atenção básica. Cad Saúde Colet. [Internet]. 2015 [citado em 08 jun 
2017]; 23(2):140-9. Disponível em: http://www.scielo.br/pdf/cadsc/v23n2/1414 -462X-cadsc-23-2-140.pdf

24. Moizes JS, Bueno SMV. Compreensão sobre sexualidade e sexo nas escolas segundo professores do ensino fundamental. Rev Esc Enferm USP. [Internet]. mar 2010 [citado em 08 jun 2017]; 44(1):205-12. Disponível em: http://www.scielo.br/pdf/reeusp/v44n1/a29 v44n1.pdf

25. Dias TYAF, Costa IKF, Melo MDM, Torres SMSGSO, Maia EMC, Torres GV. Avaliação da qualidade de vida de pacientes com e sem úlcera venosa. Rev Latinoam Enferm. [Internet]. jul/set 2014 [citado em 13 maio 2017]; 22(4):576-81. Disponível em:

http://www.scielo.br/pdf/rlae/v22n4/pt_01 04-1169-rlae-22-04-00576.pdf

26. Piropo TGN, Gomes FV, Azoubel R, Torres GV. Autocuidado de portadores de úlcera venosa crônica em ambiente domiciliar. Rev Saúde.com. [Internet]. jul/ago 2012 [citado em 18 jul 2017]; 8(2):2-11. Disponível em: http://www.uesb.br/revista/rsc/v8/v8n2a01. pdf

27. Santos LSF, Camacho ACLF, Oliveira BGRB, Nogueira GA, Joaquim FL.

Influência da úlcera venosa na qualidade de vida dos pacientes: revisão integrativa. Rev Enferm UFPE. [Internet]. abr 2015 [citado em 03 jul 2017]; 9(supl 3):7710-22. Disponível em:

https://periodicos.ufpe.br/revistas/revistaen fermagem/article/view/10512/11392

28. Silveira MGB, Coelho AR, Rodrigues SM, Soares MM, Camillo GN. Portador de hanseníase: impacto psicológico do diagnóstico. Psicol Soc. [Internet]. 2014 [citado em 13 maio 2017]; 26(2):517-27. Disponível em:

https://dialnet.unirioja.es/descarga/articulo/ 4808606.pdf

29. Gonçalves JRL, Soares PPB, Silva

CMM, Gonçalves ER, Santos EA.
Significado de vivenciar um grupo terapêutico junto a um projeto de extensão: relato de experiência. Rev Enferm Atenção Saúde [Internet]. 2013 [citado em 13 maio 2017]; 2(3):88-95. Disponível em: http://seer.uftm.edu.br/revistaeletronica/ind ex.php/enfer/article/view/243/437 30. Espíndula JA, Do Valle ERM, Bello AA. Religião e espiritualidade: um olhar de profissionais de saúde. Rev Latinoam Enferm. [Internet]. nov/dez 2010 [citado em 17 set 2017]; 18(6):[08 telas].

Disponível em: https://www.revistas.usp.br/rlae/article/vie w/4279/5429

RECEBIDO: 01/11/17

APROVADO: 03/05/18

PUBLICADO: 09/18 